\title{
Trepanning on unidirectional composites: delamination studies
}

\author{
J. Mathew ${ }^{\mathrm{a}}$, N. Ramakrishnan ${ }^{\mathrm{b}}$, N.K. Naik ${ }^{\mathrm{c}, *}$ \\ ${ }^{a}$ Department of Mechanical Engineering, Regional Engineering College, Calicut, Kerala, 673601, India \\ ${ }^{\mathrm{b}}$ Department of Mechanical Engineering, Indian Institute of Technology, Powai, Mumbai, 400076, India \\ ${ }^{\mathrm{c}}$ Department of Aerospace Engineering, Indian Institute of Technology, Powai, Mumbai, 400076, India
}

\begin{abstract}
Drilling of fibre reinforced plastics with conventional tools often results in defects like delamination, debonding, fibre pull-out, etc. Thrust is a major factor responsible for delamination and it mainly depends on tool geometry and feed rate. Trepanning tools, which were used in this study, were found to give reduced thrust while making holes on thin laminated composites. In this work the peculiarities of trepanning over drilling of unidirectional composites has been emphasised. The models for prediction of critical thrust and critical feed rate at the onset of delamination during trepanning of unidirectional composites based on fracture mechanics and plate theory also have been presented. Mathematical models correlating thrust and torque with tool diameter and feed rate have been developed through statistically designed experiments and effect of various parameters on them have been discussed. The critical feed rate is a function of strain energy release rate, elastic properties, sub-laminate thickness and diameter of the tool. It is observed that sub-laminate thickness is the most decisive parameter from the viewpoint of critical feed rates.
\end{abstract}

Keywords: Trepanning; B. Delamination

\section{Introduction}

Near-net-shape manufacturing capability of fibre reinforced plastics (FRP) along with their special properties like high specific strength and high specific stiffness make them attractive in almost all fields ranging from aerospace to consumer goods. Glass fibre reinforced plastics (GFRP), carbon fibre reinforced plastics (CFRP) and aramid fibre reinforced plastics (AFRP) are the most commonly used polymer composites in industries. Drilling is one of the most important, frequently practised and unavoidable machining operation for components used in FRP composite structures. This is considered as a process which has got high likelihood of introducing potential flaw sites in the laminated composite structures. Hence, significant resources are being expended in industry on hole preparation and inspection of fabricated composites. The material and process-related problems encountered in drilling of laminated composites are matrix burning, delamination, debonding, fibre pull-out, tool wear, etc. Many of these problems are due to the use of non-optimal cutting tool designs and machining conditions [1-8]. Current tool designs being applied in industry for drilling composites were originally developed for metal removal applications and do not take into account differences in properties of the homogeneous and non-homogeneous work materials [3,4]. Only in recent years the cutting tool manufacturers have started developing tool geometries specifically for drilling of composite materials. Four-facet, eight-facet, jo-point, inverted cone and carbide tipped drills are some of the widely used tool designs in drilling of composite materials [5-9].

While drilling with conventional drills, the crack propagation around the drilled holes is found to be more severe when the cutting lips pass through the bottom sub-laminates. Since the centre portion is already cut, the rigidity of the material decreases and the uncut fibres try to entangle with the cutting lips resulting in a twisting effect. This problem becomes more severe when drilling thin laminates because most of the drilling takes place in a transient cutting zone. Hence, there exists a need to further modify the tool geometry so as to achieve reduction of the thrust at normal feed rates. Trepanning, which is normally used for large diameter holes for metals and alloys, could be a solution to this. In view of this, the present authors [10] conceived the use of small diameter trepanning tools and conducted exploratory studies accordingly. In the case of trepanning tools, cutting action starts from the periphery of the cutting edge of the tool which puts the fibres in tension during the entire cutting operation. The fact that the fibres are 


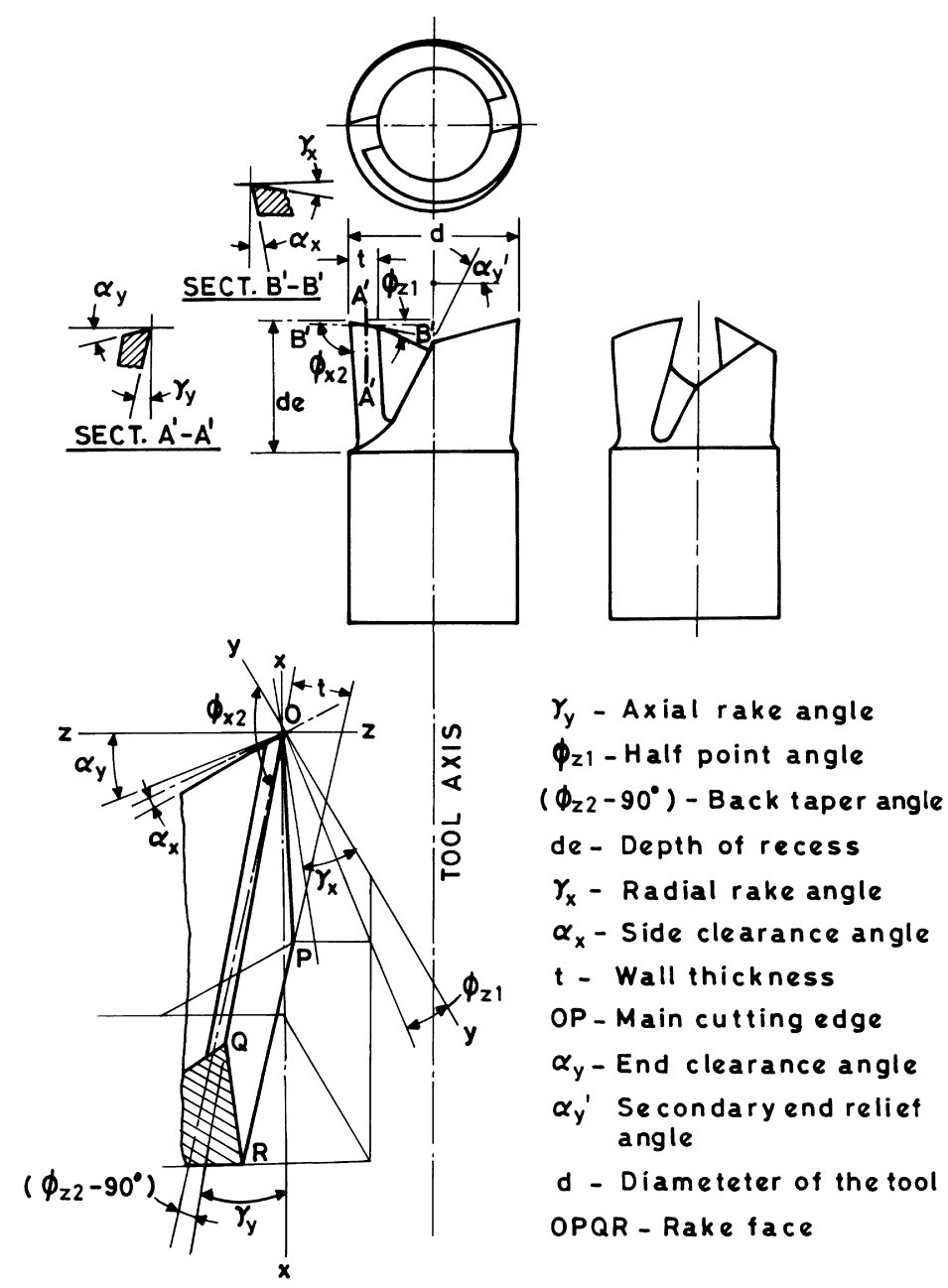

Fig. 1. Geometry of the trepanning tool [11,12].

in tension when they are being cut makes the cutting easier. This behaviour makes them superior to the twist drills and multi-facet drills. Trepanning tools are found to work well with thin laminates for making delamination-free holes $[11,12]$. The trepanning tool that has been investigated herein consisted of two cutting edges on the periphery of a hollow cylindrical shank [11,12] (Fig. 1). Radial rake angle, axial rake angle, half point angle and end clearance angle have been taken as the tool geometry parameters that influence the thrust generated and the appropriate values for which has been arrived through statistically planned experiments and analysis [12]. The wall thickness $t$ of the tool is kept constant throughout. This paper presents models for the prediction of critical thrust and critical feed rate at the onset of delamination with such tools while making holes on E-glass/epoxy unidirectional composites. The regression models for thrust and torque and the effect of various parameters on them are also presented.

\section{Theoretical background}

A theoretical model for predicting the critical conditions for onset of delamination in quasi-isotropic composites during drilling with conventional drills using linear elastic fracture mechanics (LEFM) and classical plate bending theory has been proposed by Ho-Cheng and Dharan [13]. They considered the layer of workpiece material to be removed by the tool as a circular plate of uniform thickness clamped along its periphery. Later, Jain and Yang [14,15] modified this model by incorporating the effect of anisotropy of the composites. According to these models, the thrust causing onset of delamination is a function of the sub-laminate thickness. The extent of damage will be more near the drill exit edge. DiPaolo et al. [16] argued that the assumption of a critical steady state thrust force being directly related to the onset of the crack position outside of the drill is an oversimplification of the crack growth phenomenon occurring while drilling FRP composites. They identified three significant damage mechanisms which cause the growth of delamination such as plate bulge, crack opening and fibre tearing/twisting. A bulge is described as an opening mode of fracture, Mode I, produced by a distributed load acting directly from the chisel edge onto a plate. After the chisel edge exits the laminate, pieces 


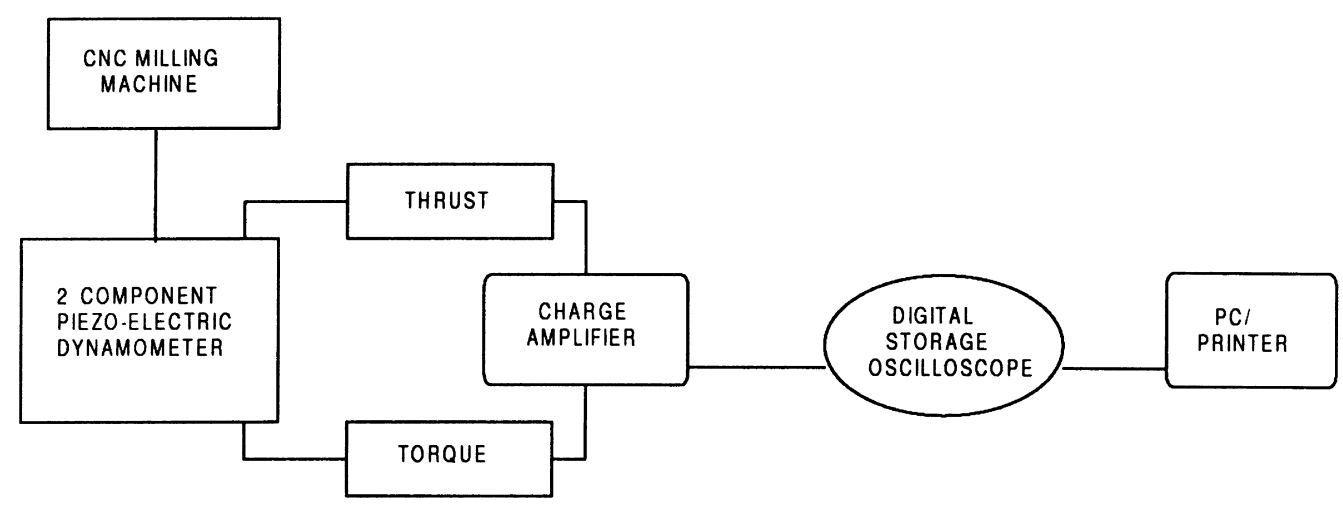

Fig. 2. Schematic diagram of the experimental set-up.

of fibres from this exit surface of the laminate start breaking off. Another opening mode of fracture is produced by a point load at the point of contact of the cutting lip and fibres. The third type of damage is fibre tearing and twisting. The cut fibres are subjected to a tearing fracture mode, Mode III as a result of the drill torque and twisting of the fibres due to the combination of the downward thrust force direction and the back rake angle along the cutting lips. At the point in time when only the cutting lips are machining, the crack position becomes larger than the drill radius and cracking outside the hole radius is realised. When the cutting lips complete their machining, the flutes act on the fibres with energy large enough to propagate the crack even further. Propagation continues until the crack gets stabilised [17].

\section{Mathematical models}

Thrust and torque are dependent on the cutting speed and the feed rate. The maximum thrust $P$ during drilling of unidirectional graphite-epoxy composites was found to increase with the diameter $d$ and the feed per revolution $f$, rather than the linear feed $[12,15]$. The model proposed for maximum thrust by Jain and Yang [15] was;

$P=0.136 H_{\mathrm{B}} d^{0.78} f^{0.4}$

where $H_{\mathrm{B}}$ is the Brinell hardness of the material in $\mathrm{kg} / \mathrm{mm}^{2}$, $d$ is in $\mathrm{mm}$ and $f$ is in $\mathrm{mm} / \mathrm{rev}$. Further, it was indicated that $P$ varied with $f^{0.317}$ for cross-ply laminates and $f^{0.224}$ for quasi-isotropic laminates.

Veniali et al. showed that the thrust strongly depends upon the diameter and weakly depends upon feed rate [18]. When drilling woven fabric AFRP composites with an inverted type twist drill, the thrust was found to vary with $d^{0.95}$ and $f^{0.25}$, while the torque was found to be varying as $d^{2.4}$ and $f^{0.4}$. Since the cutting action of such tools is mainly concentrated at the periphery, the torque is expected to grow with the tool diameter more rapidly than in traditional tools with straight cutting edge. Bhatnagar et al. [8] showed that, when drilling UD-CFRP, the thrust increased as $f^{0.5}$ with a four-facet solid carbide drill and as $f^{0.42}$ for an eight-facet drill. These results are in agreement with those of Jain and Yang [15]. The experimental results of HoCheng et al. [19] on drilling of carbon fibre reinforced acrylonitrile butadiene styrene (ABS) showed that both the maximum thrust and the maximum torque are proportional to $f^{0.88}$ and that with this material a significant amount of plastic deformation of the matrix material is observed during chip formation. During drilling, torque increases rapidly until the cutting edges of the tool are completely engaged. It then increases linearly until a maximum value is reached and is followed by a slight drop after hole completion [16]. The large difference between the cutting torque and maximum torque is attributed to high frictional forces between the lands of the drill and the wall of the hole. High temperatures and slightly negative coefficients of thermal expansion compound the problem by squeezing the drill with graphite-epoxy [19,20]. Increase in diameter and feed rate increases the torque whereas an increase in the point angle of the drill produces a decrease in torque [3].

In summary, the mathematical models developed so far showed that the thrust and torque are functions of diameter of the tool and feed rate. As reported in most of the models in the literature, the feed rate, expressed as $\mathrm{mm} / \mathrm{rev}$, has been found to be an influential input parameter in this study as well. Since the feed is less than unity, from Eq. (1) it can be seen that as the power of $f$ increases, maximum thrust $P$ would decrease. In contrast, since diameter is greater than unity, as the power of $d$ increases, maximum thrust $P$ also would increase. The $d / h$ ratio (ratio of diameter of tool to thickness of the composite) is another factor to be considered during the modelling and analysis. It can be seen that with standard twist drill of cone angle $118^{\circ}$, the thrust reaches a peak value during drilling in cases when $d / h$ ratio exceeds 3.32 . The drilling gets completed during the transient cutting zone itself in cases where the $d / h$ is lower than 3.32. Meanwhile tools with smaller cone angles will have steady cutting conditions due to smaller $d / h$ ratios. 


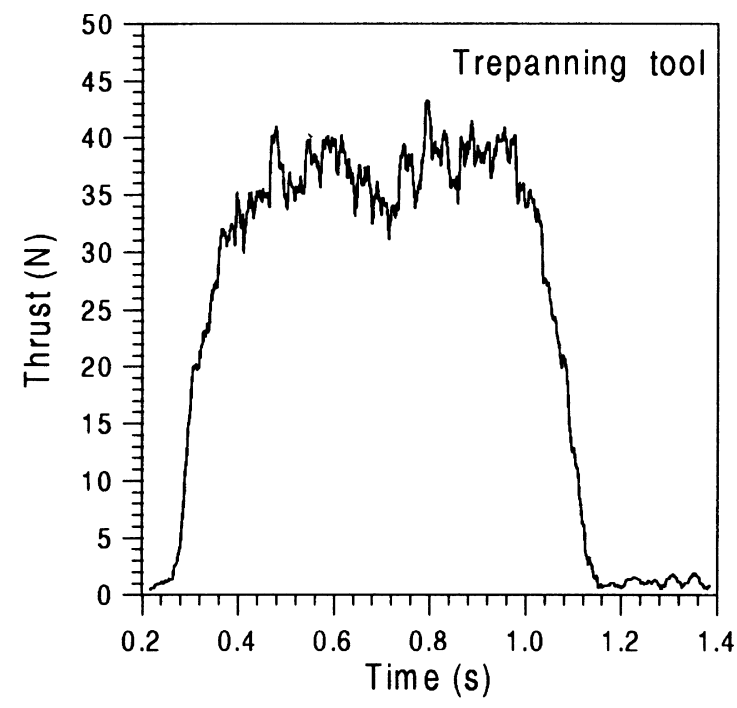

(a) Trepanning tool

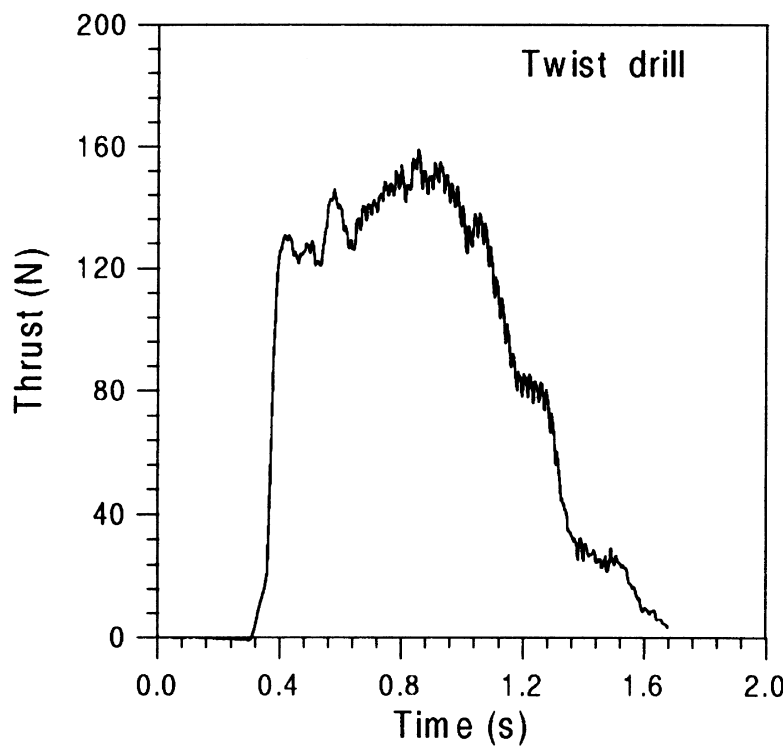

\section{(b) Twist drill}

Fig. 3. Thrust versus time for the entire drilling cycle $(d=10 \mathrm{~mm}, v=$ $50 \mathrm{~m} / \mathrm{min}, f=0.2 \mathrm{~mm} / \mathrm{rev}$ ).

Table 1

Multiple regression analysis, dependent variable: $\ln (P)$

\begin{tabular}{lll}
\hline Parameter & Estimate & $P$-value \\
\hline Constant & 3.8910 & 0.0000 \\
$\ln (d)$ & 0.2418 & 0.0124 \\
$\ln (f)$ & 0.3700 & 0.0000 \\
\hline
\end{tabular}

Table 2

ANOVA for $\ln (P)$

\begin{tabular}{lrrlll}
\hline Source & Sum of squares & d.f & Mean square & $F$-ratio & $P$-value \\
\hline Model & 12.9325 & 2 & 6.4663 & 164.70 & 0.0000 \\
Residual & 2.2378 & 57 & 0.0392 & & \\
Total & 15.1703 & 59 & & & \\
\hline
\end{tabular}

Table 3

Multiple regression analysis, dependent variable: $\ln (T)$

\begin{tabular}{lrl}
\hline Parameter & Estimate & $P$-value \\
\hline Constant & -3.2700 & 0.0000 \\
$\ln (d)$ & 1.5715 & 0.0000 \\
$\ln (f)$ & 0.5900 & 0.0000 \\
\hline
\end{tabular}

Table 4

ANOVA for $\ln (T)$

\begin{tabular}{lcrccc}
\hline Source & Sum of squares & d.f & Mean square & $F$-ratio & $P$-value \\
\hline Model & 34.6025 & 2 & 17.3012 & 522.44 & 0.0000 \\
Residual & 1.8876 & 57 & 0.0331 & & \\
Total & 36.4901 & 59 & & & \\
\hline
\end{tabular}

\section{Experiments, results and discussion}

The composites used in the experiments are of UD-GFRP contains E-glass fibres as reinforcing material and epoxy as the matrix. It consisted of a resin (LY-556) and a hardener (HY-951), both manufactured by Ciba-Giegy (India). Due to low cure shrinkage, laminates are dimensionally stable and free from internal stress. Hardener HY-951 facilitates curing at room temperature in $20-24 \mathrm{~h}$. The pot life of mixture of epoxy resin and hardener is between 30 and $60 \mathrm{~min}$. The laminate was made by matched-die moulding. Care was taken to ensure complete wetting of fibres and after application of resin, air inclusion and excess resin were removed. The thickness is $4 \mathrm{~mm}$ with each ply of thickness $0.228 \mathrm{~mm}$ and a nominal fibre volume fraction of 0.4 .

Experiments were conducted on a DECKEL CNC milling machine with the trepanning tools and twist drills of diameters $8,10,14$ and $16 \mathrm{~mm}$ at cutting speeds of 20,50 and $80 \mathrm{~m} / \mathrm{min}$ and feed rates of $0.01,0.05,0.10,0.15$ and $0.20 \mathrm{~mm} / \mathrm{rev}$. Schematic diagram of the experimental set-up is given in Fig. 2. The detailed experimental procedure and signal processing details have been explained by the authors in another paper [12]. Typical thrust signals generated by identical diameter trepanning tool and twist drill are shown in Fig. 3(a) and (b), respectively. It can be seen from these figures that because of the presence of conical point, twist drills take more time to complete the cutting process. The average of 10 peak values in the signal was taken for further analysis [12]. Similarly, torque signals were also analysed. The effect of cutting speed $(v)$ is found to be insignificant between 50 and $80 \mathrm{~m} / \mathrm{min}$ [12]. Hence, further experiments 


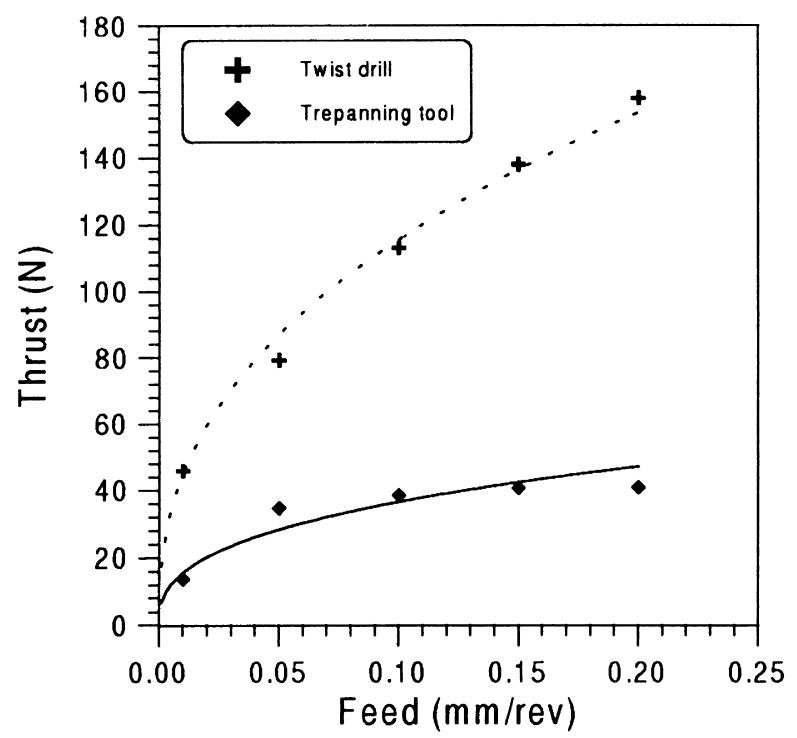

(a) Thrust

[R-squared $99.1 \%$, adjusted R-squared $98.9 \%$ for twist drill; R-squared $90.5 \%$, adjusted R-squared $87.73 \%$ for trepanning tool]

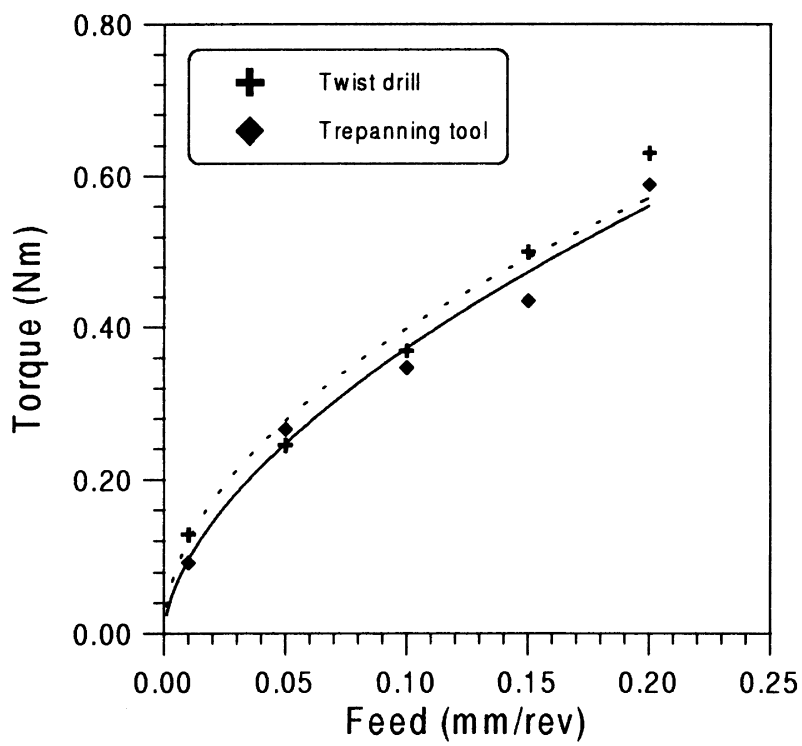

(b) Torque

[R-squared $97.8 \%$, adjusted R-squared $96.1 \%$ for twist drill; R-squared $99 \%$, adjusted R-squared $97.2 \%$ for trepanning tool]

Fig. 4. Comparison between trepanning tool and twist drill $(d=10 \mathrm{~mm}, v=50 \mathrm{~m} / \mathrm{min})$. 


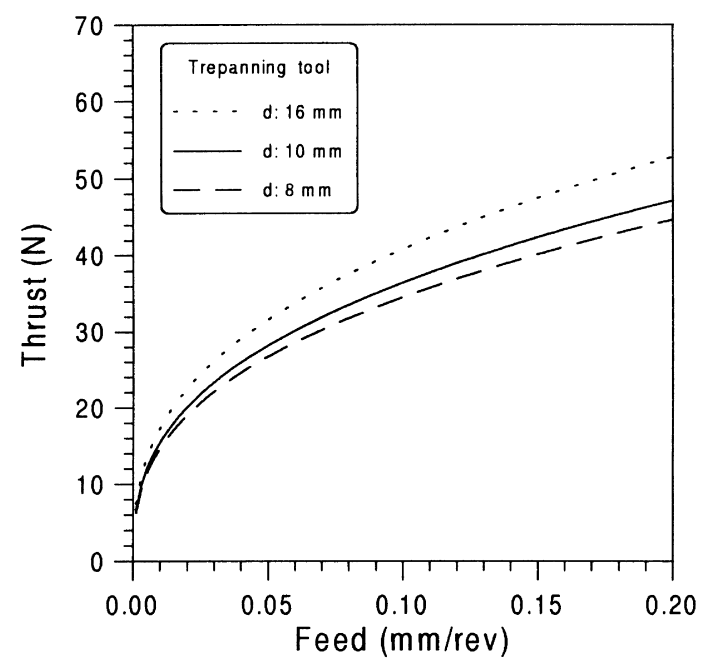

(a) Trepanning tool

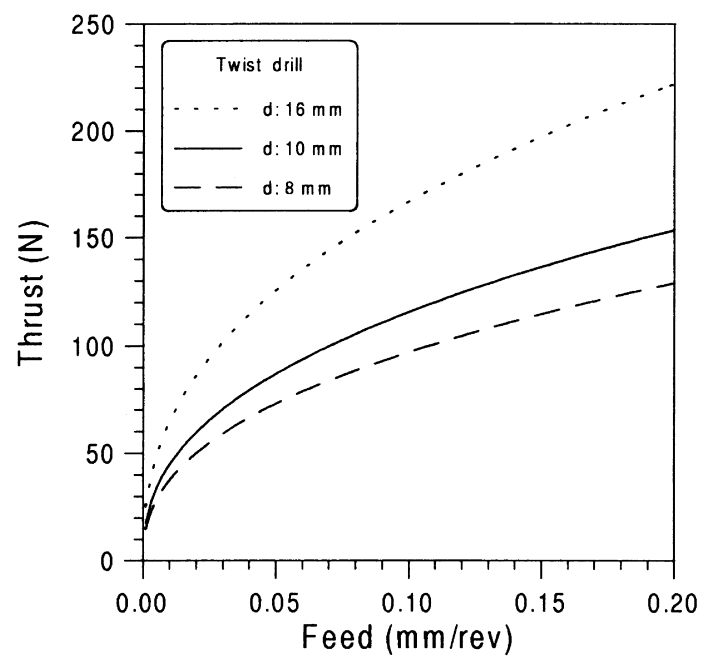

(b) Twist drill

Fig. 5. Effect of diameter of tool on thrust based on predicted equation $(v=$ $50 \mathrm{~m} / \mathrm{min}$ ).

were done at a constant cutting speed of $50 \mathrm{~m} / \mathrm{min}$. The results of the above full factorial experiments were subjected to regression analysis to build the most suitable mathematical model between the response (thrust/torque) and the independent variables (diameter and feed) [21]. Logarithmic models have been found to fit well in this case. The results of the multiple regression analysis and the analysis of variance (ANOVA) is as shown in Tables 1-4 and these confirm the adequacy of the model. ANOVA is a statistical method used to establish the relative significance of the individual independent variables as well as their interaction effects on the behaviour of the response variables. It is based on the least-squares approach; the

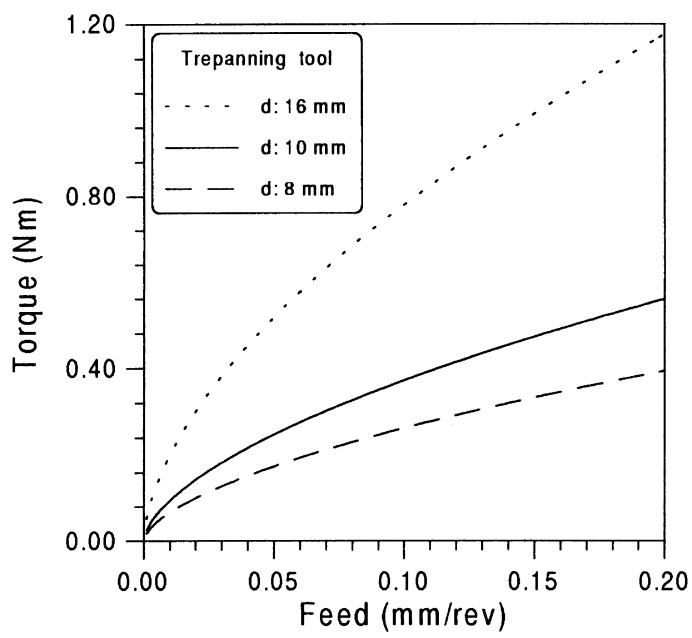

(a) Trepanning tool

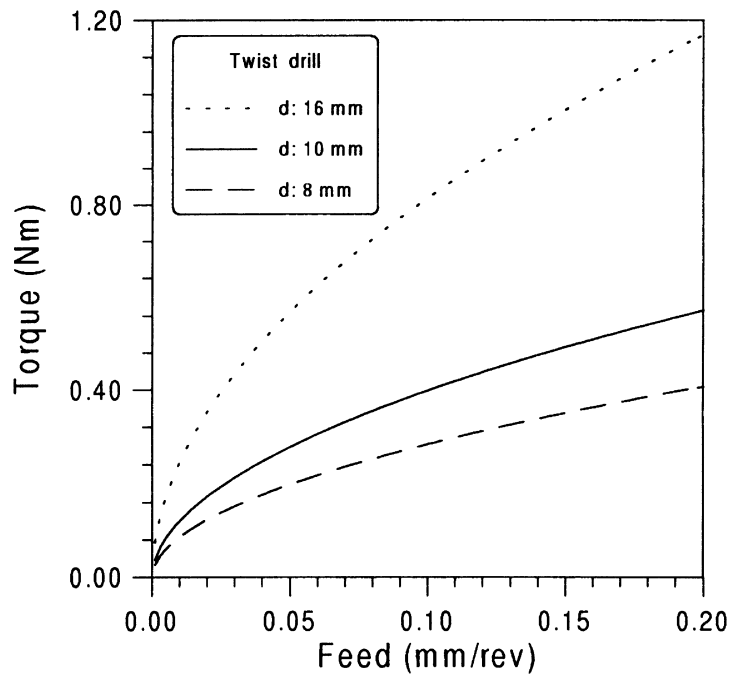

(b) Twist drill

Fig. 6. Effect of diameter of tool on torque based on predicted equation $(v=$ $50 \mathrm{~m} / \mathrm{min}$ )

error variance is equal to the minimum value of the sum of squares about some reference value divided by the degrees of freedom (d.f). Where, the degrees of freedom is equal to number of independent elements employed in calculating that statistic. The value of the variance ratio $(F$-ratio) and its probability ratio ( $P$-ratio) gives the relative significance of individual factors and their interactions. The $P$-values are very small and indicating the statistical significance of the model and individual factors. The mathematical models for trepanning tools derived from the ANOVA are given below.

$$
\begin{aligned}
& \ln (P)=3.891+0.242 \ln (d)+0.37 \ln (f) \\
& \ln (T)=-3.27+1.571 \ln (d)+0.59 \ln (f)
\end{aligned}
$$




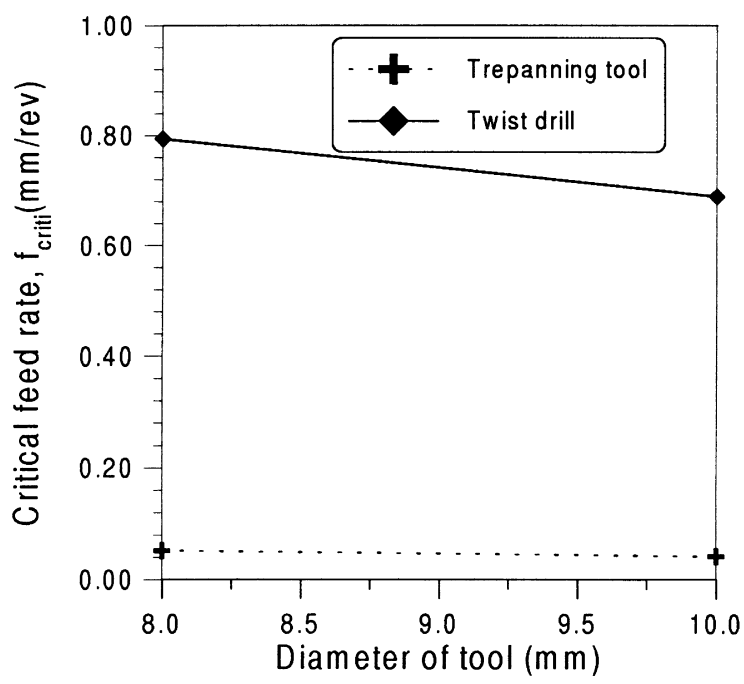

Fig. 7. Comparison of predicted critical feed rate with twist drills and trepanning tools $\left(h=0.228 \mathrm{~mm} ; P_{\text {crit }}=74.66 \mathrm{~N}\right)$.

where, $P$ is in $\mathrm{N}, T$ is in $\mathrm{Nm}, d$ is in $\mathrm{mm}$ and $f$ is in $\mathrm{mm} / \mathrm{rev}$.

Correspondingly, the exponential equation for thrust and torque for trepanning tool can be written as:

$P=48.98 d^{0.242} f^{0.37}$

$T=0.039 d^{1.571} f^{0.59}$

In order to get a comparative study, the constants in the Eqs. (4) and (5), which are mainly material dependent properties, are kept the same for the twist drill case. The corresponding equations for twist drill are:

$P=48.98 d^{0.783} f^{0.410}$

$T=0.039 d^{1.529} f^{0.52}$.

Comparison of thrust and torque between trepanning tools and twist drill of $10 \mathrm{~mm}$ diameter is given in Fig. 4(a) and (b), respectively. The $R$-squared and adjusted $R$ squared values are also given along with Fig. 4 . $R$-squared value indicates the proportion of the variability in the data. The high values of $R$-squared and closeness of adjusted $R$ squared with $R$-squared show the adequacy of the model. The $R$-squared statistic for Fig. 4(a) indicates that the model of twist drill explains $99.1 \%$ of the variability in thrust whereas in trepanning tool there is $90.5 \%$ of the variability in thrust. Fig. 4(a) shows that thrust developed by trepanning tools is always lower than that with twist drills in the experimental region. The decrease in the exponential indices of diameter from 0.783 to 0.242 with trepanning tools explains that the diameter of the tool has relatively less influence in trepanning tools. The material removal from the annular region near the outer diameter could be the reason for such a decrease. The volume of the material removed by same diameter trepanning tool becomes almost half when compared with conventional tools. The ability to cut the material with high feed rate at lower thrust is an added advantage with trepanning tools. Fig. 4(b) describes the effect on torque. It can be seen that there is hardly any reduction in torque when the tool geometry is changed from conventional drill to trepanning type.

Fig. 5(a) and (b) explain the effect of increase in diameter with respect to trepanning tool as well as twist drill. In the case of trepanning tool, Fig. 5(a) shows that the effect of change of diameter on thrust in insignificant. In contrast, Fig. 5(b) for twist drills shows that the change of tool diameter has significant influence on the thrust. Similarly, the effect of variation in diameter on torque is explained in Fig. 6(a) and (b). There is a significant effect on torque, particularly at higher values of tool diameter.

\section{Prediction of critical feed rate}

As considered in Ho-Cheng and Dharan's model [13], the layer of the workpiece material not yet removed by the tool was considered as a circular plate of uniform thickness, clamped along its periphery. Since the thrust force tends to cause a tension detachment of the border of the sub-laminate, the cause of the delamination can be attributed to this thrust, disregarding the effect of torque. In the case of UD laminates, the plate is stiffer in the fibre direction. Therefore for the same tool movement, the stresses developed along the fibre direction are more. And this will result in a longer delamination along the fibre direction compared to the transverse direction. Hence, the shape of the delamination will be more like elliptical than circular [14]. But in the present analysis, the assumption of circular shaped delamination is taken for simplicity and moreover it has been accepted as a conservative model for such an analysis. The formula for critical thrust for delamination $\left(P_{\text {crit }}\right)$, obtained from linear elastic fracture mechanics, is given by [13]

$P_{\text {crit }}=\pi \sqrt{\frac{8 G_{\mathrm{IC}} E_{11} h^{3}}{3\left(1-\nu_{12}^{2}\right)}}$

where $G_{\mathrm{IC}}$ is the critical strain energy release rate, $E_{11}$ is the modulus of elasticity along the fibre direction, $h$ is the sublaminate thickness and $\nu_{12}$ is the Poisson's ratio. Experiments were conducted so as to find out the value of $G_{\mathrm{IC}}$ of the unidirectional composites as per ASTM standards [22]. $G_{\mathrm{IC}}$, as determined from these experiments, is $440 \mathrm{~J} / \mathrm{m}^{2}$. The values of other parameters are: $E_{11}=36.38 \mathrm{GPa} ; \nu_{12}=$ 0.323 and $h=0.228 \mathrm{~mm}$.

In the above model, the thrust force due to the tool is assumed to be acting as a point load at the centre of the circular plate. The same models hold good for small diameter trepanning tools also. Hence, it can be seen that the critical thrust for initiation of delamination depends only on material properties and is independent of the diameter of 


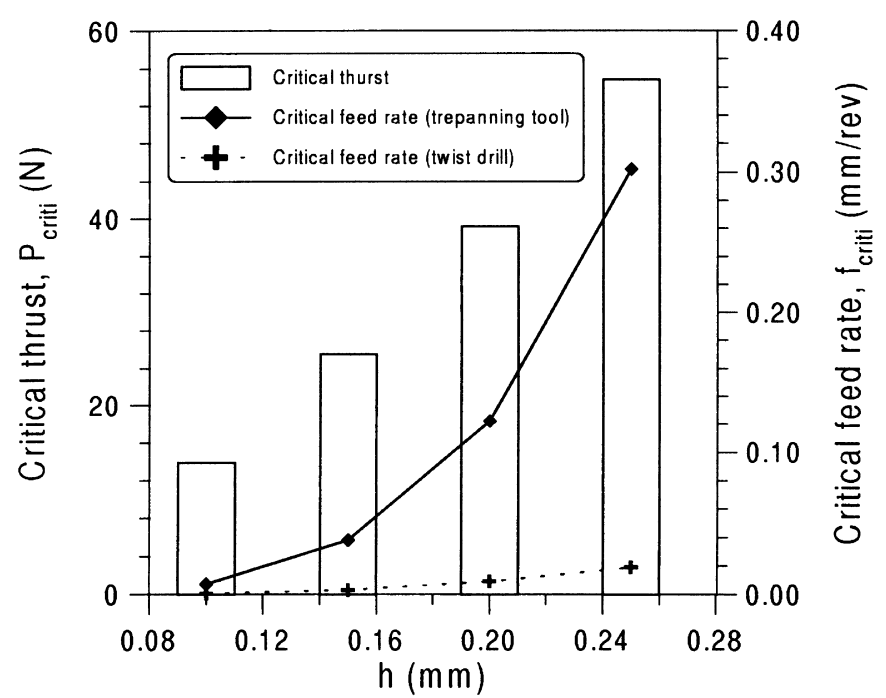

(a) for $\mathrm{G}_{\mathrm{IC}}=180 \mathrm{~J} / \mathrm{m}^{2}$

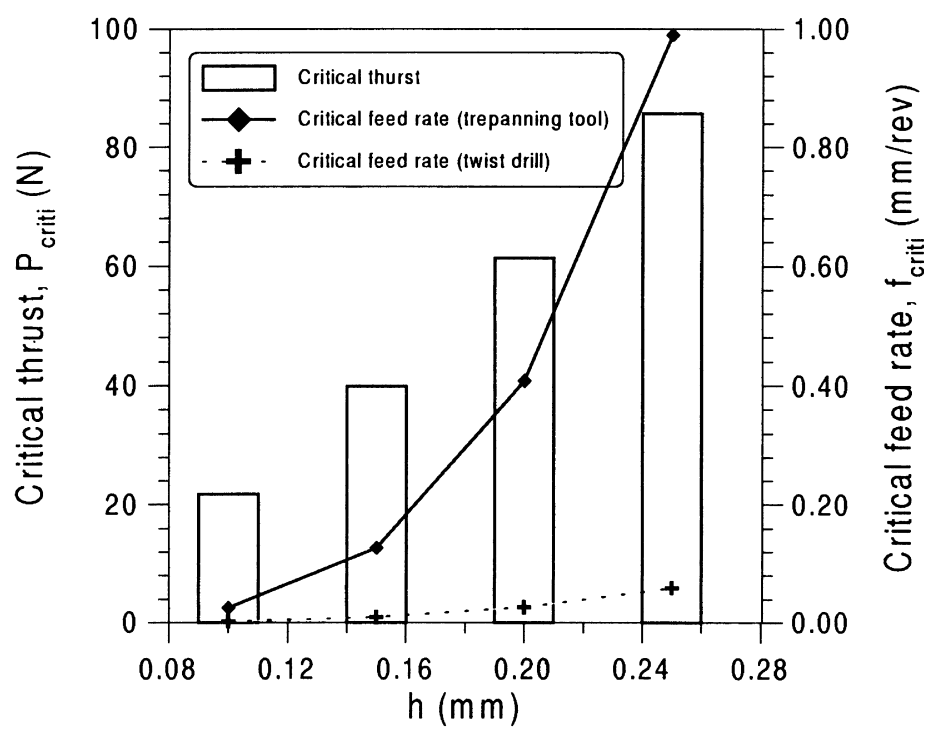

(b) for $\mathrm{G}_{\mathrm{IC}}=440 \mathrm{~J} / \mathrm{m}^{2}$

Fig. 8. Parametric studies: effect of $G_{\mathrm{IC}}$ and $h$ on various critical values $\left(E_{11}=36.38 \mathrm{GPa} ; \nu_{12}=0.323 ; d=10 \mathrm{~mm}\right)$.

the tool. Here, the calculated value of critical thrust for initiation of delamination corresponding to bottom ply is 74.66 N. Comparing Eqs. (4) and (8), the critical feed rate $\left(f_{\text {crit }}\right)$ with trepanning tools is given by

$f_{\text {crit }}=\left\{\frac{\pi}{48.98 d^{0.242}} \sqrt{\frac{8 G_{\mathrm{IC}} E_{11} h^{3}}{3\left(1-\nu_{12}^{2}\right)}}\right\}^{2.7}$.

Similarly comparing Eqs. (6) and (8), the critical feed rate with twist drills is given by

$$
f_{\text {crit }}=\left\{\frac{\pi}{48.98 d^{0.783}} \sqrt{\frac{8 G_{\mathrm{IC}} E_{11} h^{3}}{3\left(1-\nu_{12}^{2}\right)}}\right\}^{2.44} .
$$

The critical feed rate at the onset of delamination has been found to be a function of tool diameter and material properties. Based on the above equations (Eqs. (9) and (10)), the $f_{\text {crit }}$ for bottom ply corresponding to different diameters of twist drills and trepanning tools are calculated and are presented in Fig. 7. This graph shows that in case of the trepanning tools one can 
use feed rates almost 16 times those in the twist drills resulting in substantial increase in the productivity.

\section{Parametric studies}

The effect of $G_{\mathrm{IC}}$ and $h$ on critical thrust and critical feed rates for same diameter trepanning tools and twist drills are evaluated and compared in Fig. 8(a) and (b). An increase of $G_{\mathrm{IC}}$ from 180 to $440 \mathrm{~J} / \mathrm{m}^{2}$ increases critical thrust 1.5 times for both trepanning tools and twist drills. Whereas the effects of the same on critical feed rates are, 3.5 times for trepanning tools and 3 times for twist drills. With an increase of sub-laminate thickness from 0.1 to $0.25 \mathrm{~mm}$, the critical thrust increases by 4 times for both trepanning tools and twist drills. But the effects of the above increase of sub-laminate thickness on critical feed rates are, 40 times for trepanning tools and 28 times for twist drills. Hence it is observed that the sub-laminate thickness is the most decisive parameter from the viewpoint of critical feed rates.

\section{Conclusions}

Models for predicting critical thrust and critical feed rate at the onset of delamination with the trepanning tool during hole making on UD-GFRP composites have been presented in this work. The difference between trepanning and by drilling with conventional drills is also explained. The thrust and torque models correlating feed rates and diameter were developed by statistical regression techniques. The $G_{\mathrm{IC}}$ value was determined by DCB testing procedure. The critical feed rate is a function of strain energy release rate, elastic properties, sub-laminate thickness and diameter of the tool. The sub-laminate thickness is the most influential parameter that decides the critical feed rates. For the unidirectional composites investigated, it has been seen that one can use feed rates almost 16 times those in the twist drills resulting in substantial increase in the productivity.

\section{References}

[1] König W, Wulf C, Graß P, Willercheid H. Machining of fibre reinforced plastics. Annals of the CIRP 1985;34(2):537-548.

[2] Mehta M, Reinhart TJ, Soni AH. Effect of fastener hole drilling anomalies on structural integrity of PMR-15/Gr composite laminates. In: Srivatsan TS, Lane CS, Bowden DM, editors. Machining of composite materials. Proceedings of Machining of Composite Materials Symposium, ASM Materials Week, Chicago, IL, 1992, pp. 113126.

[3] Miller JA. Drilling graphite/epoxy at Lockheed. American Machinist and Automated Manufacturing 1987;October:70-71.
[4] Gindy NN. Selection of drilling conditions for glass fibre reinforced plastics. International Journal of Production Research 1988;26(8):1317-1327.

[5] Komanduri R. Machining fibre reinforced composites. Mechanical Engineering. 1993;April:58-64.

[6] Abrate S. Machining of composite materials. In: Mallick PK, editor. Composites engineering handbook, New York: Marcel Dekker, 1997. pp. 777-784.

[7] Park KY, Choi JH, Lee DG. Delamination-free and high efficiency drilling of carbon fibre reinforced plastics. Journal of Composite Materials 1995;29(15):1988-2002.

[8] Bhatnagar N, Naik NK, Ramakrishnan N. Experimental investigations of drilling on CFRP composites. Materials and Manufacturing Processes 1993;8(6):683-701.

[9] Bhatnagar N, Naik NK, Ramakrishnan N. Some studies on an inverted cone drill for FRP drilling. In: Srivatsan TS, editor. Engineering systems design and analysis, ASME PD, 64(2) 1995, pp. 1-7.

[10] Mathew J, Ramakrishnan N, Naik NK. Drilling of UD composites with trepanning tools: preliminary investigations. In: Mujumdar PM, Joshi A, editors. Advances in testing, design and development of aerospace structures, Proceedings of the Fifth NASAS, Bombay, 1996, pp. 247-252.

[11] Mathew J, Ramakrishnan N, Naik NK. Hole making on GFRP with trepanning tools: cutting mechanisms and hole quality. Presented at the 17th AIMTDR Conference, Warangal, India, January 1997.

[12] Mathew J, Ramakrishnan N, Naik NK. Investigations into the effect of geometry of a trepanning tool on thrust and torque during drilling of GFRP composites. Journal of Materials Processing Technology 1999, in press.

[13] Ho-Cheng H, Dharan CKH. Delamination during drilling in composite laminates. Transactions of the ASME: Journal of Engineering For Industry 1990;112:236-239.

[14] Jain S, Yang DCH. Effects of feed rate and chisel edge on delamination composite drilling. Transactions of the ASME: Journal of Engineering for Industry 1993;115:398-405.

[15] Jain S, Yang DCH. Delamination-free drilling of composite laminates. Transactions of the ASME: Journal of Engineering for Industry 1994;116:475-481.

[16] DiPaolo G, Kapoor SG, DeVor RE. An experimental investigation of the crack growth phenomenon for drilling of fibre-reinforced composite materials. Transactions of the ASME: Journal of Engineering for Industry 1996;118:104-110.

[17] Caprino G, Tagliaferri V. Damage development in drilling glass fibre reinforced plastics. International Journal of Machine Tools and Manufacture 1995;35(6):817-829.

[18] Veniali F, Dillio A, Tagliaferri V. An experimental study of the drilling of aramid composites. Transactions of the ASME: Journal of Energy Resources Technology 1995;117:271-277.

[19] Ho-Cheng H, Puw HY, Yao KC. Experimental aspects of drilling of fibre-reinforced plastics. In: Srivatsan TS, Bowden M, editors. Machining of composite materials, Proceedings of the Machining of Composites, ASM, Illinois, 1992, pp. 127-138.

[20] Dillio A, Tagliaferri V, Veniali F. Progress in drilling of composite materials. In: Srivatsan TS, Bowden M, editors. Machining of composite materials, Proceedings of the Machining of Composites, ASM, Illinois, 1992, pp. 199-203.

[21] Montgomery DC. Design and analysis of experiments. 4. New York: Wiley, 1997.

[22] ASTM Standards D: 5528-94a, 1994. 